Available online at GSC Online Press Directory

GSC Advanced Research and Reviews e-ISSN: 2582-4597, CODEN (USA): GARRC2

Journal homepage: https://www.gsconlinepress.com/journals/gscarr

(CASE REPORT)

\title{
Lung metastasis of basal cell carcinoma on anterior chest wall: A rare case report
}

\author{
Widiastuti Soewondo 1,*, Viska W. Arianti ${ }^{1}$, Yusuf S. Nawawi ${ }^{1}$, Muchtar Hanafi ${ }^{1}$, Rita Budianti 2 and Brian \\ Wasita ${ }^{3}$ \\ 1 Department of Radiology, Dr. Moewardi Hospital/Faculty of Medicine Universitas Sebelas Maret, Indonesia. \\ ${ }^{2}$ Department of Radiotherapy Oncology, Dr. Moewardi Hospital/ Faculty of Medicine Universitas Sebelas Maret, \\ Indonesia. \\ ${ }^{3}$ Department of Pathology Anatomy, Faculty of Medicine, Universitas Sebelas Maret, Indonesia.
}

Publication history: Received on 22 November 2020; revised on 03 December 2020; accepted on 05 December 2020

Article DOI: https://doi.org/10.30574/gscarr.2020.5.3.0119

\begin{abstract}
Introduction: Metastasis of primary basal cell carcinoma (BCC) on thoracic wall is rarely reported in literatures. Metastasis of cancer to the lung is suggested of hematogenous spread to the lung. We reported the only case of metastatic BCC encountered in Dr. Moewardi Hospital Surakarta.

Case: A 62-year-old female patient was referred to our hospital with a recurrent lump on the anterior part of her chest accompanied by radiating pain to the back lasting for about a year. Previously she had undergone surgery, but the lump regrew on the similar location. Histopathology finding revealed infiltrating BCC. Chest radiograph showed miliary type pulmonal metastasis. Contrast CT-Scan imaging revealed a malignant solid mass on the anterior thoracic wall with lung metastasis, manifesting as pneumonia and left pleural effusion, in accordance to pneumonic and subpleural type pulmonal metastasis. Subsequently, patient underwent chemoradiotherapy, resulting in positive response of tumor regression.
\end{abstract}

Conclusion: Clinicians need to exercise a high index of suspicion of metastasis for the management of patient with BCC on rare sites such as anterior chest.

Keywords: Basal-cell-carcinoma; Lung; Metastasis; CT-Scan

\section{Introduction}

Basal cell carcinoma (BCC) primarily manifests as an indolent yet malignant cutaneous neoplasm originating from the basal cell layer of epidermis. Its characteristic is marked with local aggressive invasion into adjacent soft tissue structures, including the skin, muscles and bones. ${ }^{1}$ BCC represents as the most prevalent cutaneous malignancy, however cases of distant metastasis of BCC remain a rare entity in BCC clinical course. The extremely low of incidences of metastatic BCC have been reported in many literatures, which were predominantly featured in the lymph nodes, lungs, or bone. Surgery remains as the treatment of choice of primary BCC; while chemotherapy is indicated for metastatic BCC. Imaging plays a major role in the staging and follow-up of metastatic BCC. Distant metastasis from a BCC should be included in the follow-up assessment of BCC on the rare sites and prior history of cutaneous BCC. In this report, we present a case of lung metastatic from primary BCC in anterior chest wall.

\footnotetext{
${ }^{*}$ Corresponding author: Widiastuti Soewondo

Department of Radiology, Dr. Moewardi Hospital/Faculty of Medicine Universitas Sebelas Maret, Indonesia. 


\section{Methods}

A 62-year-old female was referred to Dr. Moewardi Hospital with a lump in the chest area. The lump was painful radiating to the back. She had undergone surgery a year before at the local hospital, with histopathologic finding showed infiltrative subtype of BCC. Six months following the surgery, the lump regrew. The patient again felt the pain in his chest and back. She was later referred to Dr. Moewardi Hospital for further workup. Clinical physical examination showed a $5 \times 4 \mathrm{~cm}$ lesion, with centrally ulcer bordered with slightly elevated rim, with fixed and firm consistency, overlaying on post-excision scar on her chest anterior. Chest X-ray showed miliary type pulmonary metastasis. Multislice CT scan with contrast demonstrated a mass on the sternal region of anterior chest which invades into manubrium sterni and anterior ribs of 1 and 2 bilaterally. It was also shown pneumonia and left pleura effusion, of which in accordance to pneumonic and subpleural type pulmonary metastasis. The patient was subsequently prescribed for chemotherapy and radiation therapy. Further follow up showed positive response as demonstrated by shrunken tumoral size.

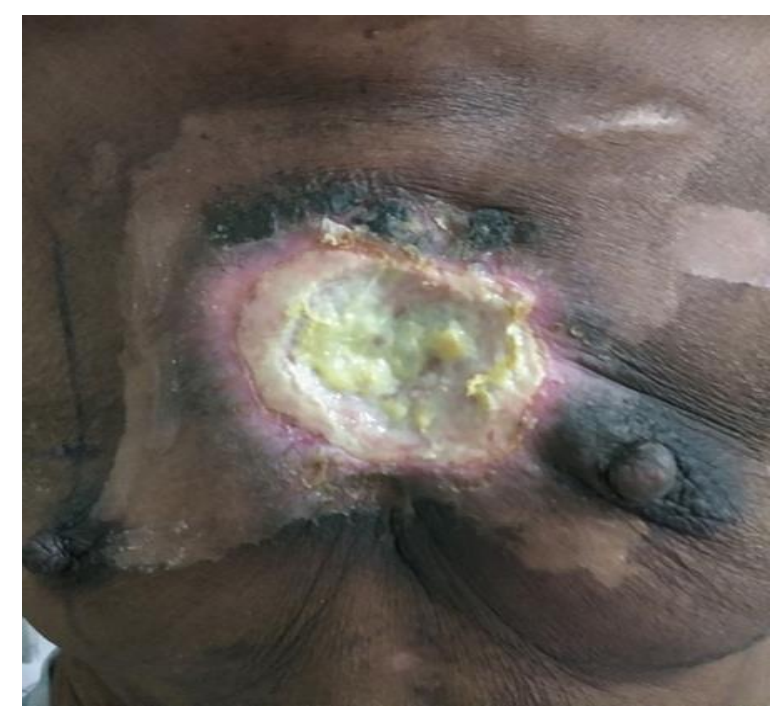

Figure 1 Physical examination on chest anterior shows a 5 x $4 \mathrm{~cm}$ of an immobile centrally ulcerated mass with slightly elevated rim. The mass has firm consistency, overlaying on post-excision scar.

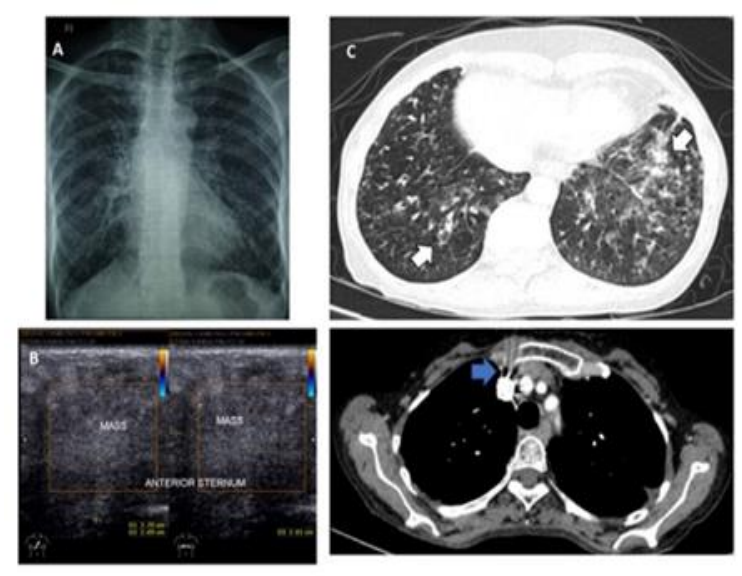

Figure 2. (from upper left counter-clockwise) A. Chest x ray reveals pneumonia on both lung fields, consistent to miliary type lung metastasis; B. Ultrasound on anterior chest shows solid ill-defined mass with irregular border. Colour doppler ultrasound demonstrates limited vascularization within the mass; C. Chest CT Scan with contrast, reveals infiltrative solid mass on sternal region with destruction of sternum bones and anterior ribs 1 and 2 (blue arrow). Other findings 
pneumonia (white arrows) and pleural effusion (not shown) which consistent to pneumonic and subpleural type pulmonal metastasis. Enlarged lymph nodes were found in both axillae (not shown).

\section{Discussion}

Basal cell carcinoma (BCC) attributes $80 \%$ of keratinocyte carcinomas, which are reported as the most common malignancies worldwide. The incidence of BCC is increasing especially for those age over 40 years, higher rate among male compared to female, Caucasian over other races and living in lower latitude over the higher ones. ${ }^{2}$ BCC mostly presents as local destructive infiltration to adjacent skin and soft tissue with only small proportion results in death or metastatic. ${ }^{3}$ There were large variation of the estimates of metastatic BCC incidence, however all literature reported extremely rare incidence of only 1 in 1,000 to $35,000 .^{4}$

Our current case is the only metastatic BCC we encounter in the past approximately five years in our institution. Presenting as a lung metastasis of primary BCC in the chest wall of an Asian female adult. It has been reported that 85\% cases of metastasis arising from the primary tumor situated in uncommon predilection sites including head and neck region, chest, back and extremities. ${ }^{5}$ Histopathologic finding of primary lesion showed infiltrative type. Despite there is no evidence if whether any histologic variety of the primary tumor will result in the difference of likelihood of recurrence or metastasis, the infiltrative type of BCC has been purportedly suggested presenting aggressive nature of BCC. ${ }^{2}$ Aggressive subtype of BCC present an increased risk of invasion into adjacent skin layers. Infiltrative subtype is characterized with distinct stromal fibrosis, dense collagen bundles, and fibroblast-rich component. Despite conventional variant classification of BCC, admixture of BCC variants attribute up to one third of all BCC cases. ${ }^{6}$

Lung ranks as the second most frequent metastatic dissemination of BCC following regional lymph nodes, followed by bones, skin and other organs via hematogenous spread or direct extension. In the advance stage of course of the disease, metastasis into liver, viscera organs and subcutaneous may occur following regional lymph nodes, lungs, or bones. ${ }^{7}$ The size of the primary tumor and the depth of tumor invasion are two determining risk factors of metastasis. ${ }^{8}$ It was reported that the larger primary tumor size pose the greater risk of metastasis as the outcome. Our patient was presented to our hospital months following her initial surgery, thus we have no recorded information about the exact size of the primary tumor. It was estimated the size of her primary lesion could be greater than $5 \mathrm{~cm}$ as evidenced from

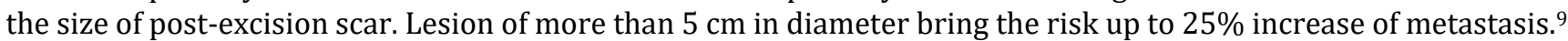

Another features could bring considerable risk of metastasis in our patient who had developed BCC at the age of late adult, its localization over skin of anterior chest area and recurrence of multiple lesions following within short interval after its initial excision. It seems that it is not necessarily the BCC over head and neck region which metastasis as has been suggested by Malone et al. ${ }^{5}$ BCC over sites other than common predilection, such as chest as in our patient, presents equal chance to metastasis. Invasion of the adjacent soft tissue and bones is rarely occurred.

Depending upon the location and extent of the tumor, treatment of choice for metastasis BCC generally consists of wide surgical excision for local infiltration and combination with chemotherapy and radiation therapy for distant metastasis. The main aim of the surgery is complete resection of the tumor with clear margins as evidenced by histopathology. The recurrence rate following surgical resection has been reportedly varies between $5 \%$ to $30 \%$ for complete excision without and with positive margins. ${ }^{7}$ Conventional chemotherapeutic drugs including cisplatin, fluorouracil, vincristine, cyclophosphamide, doxorubicin, and methotrexate have been used as single agent or in combination. In advanced and unresectable BCC, cisplatin-based chemotherapy has shown the best efficacy, both as a single agent and in combination with other chemotherapeutic agents. ${ }^{10}$

Despite the high incidence of primary BCC, the rarity of metastatic BCC has made it difficult to characterize its etiology, risk factors, and therapeutic options and efficacy. In addition to the indolence nature of BCC, perhaps has contributed to underestimation of clinical course and largely public health impact of BCC, thus result in paucity of knowledge on management of BCC. Most of published literatures were based on individual or serial case report, and very few were based on prospective study. More future epidemiological and clinical studies are demanded to strengthen fundamental body of knowledge and evidence of, specifically risk factors, diagnosis, therapeutic efficacy and prevention.

\section{Conclusion}

In practical clinical view, diagnosis and therapy of all cases of BCC at the earliest is imperative to provide the best efficacious treatment and prevent possibility of metastasis in the future. Clinicians need to exercise a high index of suspicion of metastasis for the management of patient with BCC on rare sites such as anterior chest. 


\section{Compliance with ethical standards}

\section{Acknowledgments}

We would like to thank to the patient who has been the subject of this report.

\section{Disclosure of conflict of interest}

There is no conflict of interests. The author reports no conflicts of interest in this work. By this statement, all authors who consist of Viska W. Arianti, Yusuf S. Nawawi, Muchtar Hanafi, Rita Budianti, Brian Wasita have no conflict of interest regarding this manuscript publication.

\section{Statement of informed consent}

Informed consent was obtained from the patient whose data mentioned in the study.

\section{References}

[1] Nakayama M, Tabuchi K, Nakamura Y, Hara A. Basal Cell Carcinoma of the Head and Neck. J Skin Cancer. 2011; 19.

[2] Cameron MC, Lee E, Hibler BP, et al. Basal cell carcinoma: Epidemiology; pathophysiology; clinical and histological subtypes; and disease associations. J Am Acad Dermatology. 2019; 80(2): 303-317.

[3] Marzuka AG, Book SE. Basal Cell Carcinoma: Pathogenesis, Epidemiology, Clinical Features, Diagnosis, Histopathology, and Management. Yale J Biol Med. 2015; 88: 167-179.

[4] Domarus HV, Stevens PJ. Metastatic basal cell carcinoma: Report of five cases and review of 170 cases in the literature. J Am Acad Dermatol. 1984.

[5] Malone P, Fedok FG, Belchis AD, Maloney ME. Basal cell carcinoma metastatic to the parotid: report of a new case and review of the literature. Ear, Nose Throat J. 2000; 79(7): 511-515.

[6] Lau J, Guminski A, Gill A, Veivers D. Metastatic basal cell carcinoma: a review of six cases. Aust J Otolaryngol. 2018; 1: $20-20$.

[7] Akinci M, Aslan S, Markoç F, Cetin B, Cetin A. Metastatic basal cell carcinoma. Acta Chir Belg. 108(2): 269-272.

[8] Randle HW. Basal cell carcinoma. Identification and treatment of the high-risk patient. Dermatol Surg. 1996; 22(3): 255-261.

[9] Snow SN, Sahl W, Lo JS, et al. Metastatic basal cell carcinoma. Report of five cases. Cancer. 1994.

[10] Fecher LA. Systemic Therapy for Inoperable and Metastatic Basal Cell Cancer. Curr Treat Options Oncol. 2013; 14(2): 237-248. 